\title{
Decolonising practices: can journalism learn from health care to improve Indigenous health outcomes?
}

\section{Efforts to decolonise health care practice and research also hold lessons for journalists and the media industry}

T he ongoing effects of colonisation are widely acknowledged as contributing to intergenerational trauma, disadvantage and poor health among Aboriginal and Torres Strait Islander peoples. ${ }^{1-3}$ Colonisation disrupted peoples' connection to country, to culture, to communities and to families through policies that sought to control, stigmatise and intervene in people's lives. Historically, doctors and other health professionals have been involved in colonising practices that have been detrimental to Aboriginal and Torres Strait Islander communities and peoples. ${ }^{4}$ Health and medical research also has a longstanding record of perpetuating rather than mitigating the impacts of colonisation, for example, by portraying Aboriginal and Torres Strait Islander peoples as "passive, powerless victims". 5

Indigenous researchers, health professionals and organisations have been at the forefront of efforts to decolonise health care practice and research in order to tackle harmful attitudes and practices that continue to contribute to poor health and lack of access to culturally respectful and appropriate care. ${ }^{1-3}$ These approaches stress the importance of acknowledging the role of one's own profession and related institutions in colonisation. Awareness of one's own values and biases is an important part of culturally competent practice, as well as an understanding of other peoples' world views. ${ }^{1-3}$ Decolonising practices include reorientation away from problematising Indigenous peoples to a focus on strengths, capacity and resilience, and stress the importance of proper process, including allowing the time and opportunity to develop relationships and trust.

Health care practitioners and researchers are encouraged to be aware of the historical context of contemporary health issues, and to understand that "the present and the future are absolutely bound up in the past". ${ }^{6}$ Decolonising practices also include respect for Indigenous knowledge and stress the importance of reciprocity - that research and practice should reflect community priorities and explicitly aim to provide useful service.

Many parallels can be drawn between the mainstream health and media sectors, including their powerful roles in contributing to a discourse about Indigenous Australians that is based on a deficit model and reflects Western ethnocentric assumptions and institutionalised racism. This discourse dominates much public debate, despite a vibrant Indigenous community media sector, the emergence of new platforms like the Twitter account @Indigenous $X$, and the innovative use of social media by the National Aboriginal Community
Controlled Health Organisation to disseminate Indigenous health news and to develop networks and influence. ${ }^{7}$ Efforts have been made in journalism education and practice to improve media reporting of Indigenous affairs in the wake of numerous inquiries and research reports that have raised concerns over some decades. ${ }^{8-10}$ While acknowledging the diversity of media practice, particularly in this era of proliferating digital communication channels, the colonising, harmful impact of much mainstream coverage remains apparent. ${ }^{11}$

Journalism, journalism education and the media industry can learn from efforts to decolonise health care research and practice, with a view to producing journalism that better serves the interests of Aboriginal and Torres Strait Islander peoples. Indeed, it is noteworthy that Juanita Sherwood, an Aboriginal academic who began an innovative new course at the University of Technology, Sydney, in 2012, teaching decolonising methods to undergraduate communications students, has a background in the health sector. ${ }^{3} \mathrm{We}$ believe there is potential for more widespread efforts for journalism to adapt decolonising practices from the health sector, including a greater inclusion of decolonising practices in journalism education and practice. This would result in increased awareness of institutionalised racism and concerted efforts to ensure

doi: 10.5694/mjal4.00528 greater representation of Indigenous peoples - whether in newsrooms and media management, or as sources in stories, including and beyond those directly related to Indigenous affairs. It would encourage a reframing of journalistic work towards more emphasis on solutionsfocused reporting, and coverage that humanises, rather than portraying Aboriginal and Torres Strait Islander people as "the other".

As can be seen with community media like the Koori Mail, decolonising practices offer the possibility of journalism that better reflects the diversity and humanity of Aboriginal and Torres Strait Islander peoples. It also would lead to the revision of media style guides that continue to perpetuate terminology viewed as offensive by many Aboriginal and Torres Strait Islander peoples, from easily addressed issues such as "indigenous" (lower case " $\mathrm{i}$ ") to the more insidious problems of racist stereotyping..$^{12}$ In the sphere of health journalism, it would reframe the narrative so that Indigenous health is reported in a much wider context. Connections to country and culture, the importance of social and emotional wellbeing, and the impact of racism and stigma would receive far more attention as important health issues. ${ }^{13}$

Efforts to decolonise journalism thus have the potential to reframe public debate in ways that might directly benefit the health of Aboriginal and Torres Strait 
Islander peoples. A mainstream media discourse that acknowledges the strengths, culture and knowledge of Aboriginal and Torres Strait Islander peoples may bring benefits for the social and emotional wellbeing of individuals and communities, as well as encouraging a focus on culturally appropriate and safe health care practices and services. Given that the limited news frames of much mainstream media coverage have been associated with a narrowing of policy options in Indigenous affairs, ${ }^{14}$ decolonising practices may also result in journalism that encourages healthier policy outcomes for Indigenous Australians.

Acknowledgements: We thank Juanita Sherwood and the members of the Aboriginal and Torres Strait Islander advisory committee for Melissa Sweet's PhD - Alwin Chong, Kathleen Musulin, Richard Weston and Renee Williams - for reviewing this article.

Competing interests: No relevant disclosures.

Provenance: Not commissioned; externally peer reviewed.

1 Dudgeon P, Milroy H, Walker R, editors. Working together: Aboriginal and Torres Strait Islander mental health and wellbeing principles and practice. 2nd ed. Canberra: Commonwealth of Australia, 2014.

2 Taylor K, Guerin P. Health care and Indigenous Australians: cultural safety in practice. Melbourne: Palgrave Macmillan, 2013.

3 Sherwood J, Edwards T. Decolonisation: a critical step for improving Aboriginal health. Contemp Nurse 2006; 22: 178-190.

4 Parsons M. Fantome Island Lock Hospital and Aboriginal venereal disease sufferers 1928-45. Health History 2008; 10: 41-62.

5 Thomas DP. Reading doctors' writing: race, politics and power in Indigenous health research 1870-1969. Canberra: Aboriginal Studies Press, 2004
6 National Health and Medical Research Council. Values and ethics: guidelines for ethical conduct in Aboriginal and Torres Strait Islander health research. Canberra: Commonwealth of Australia, 2003. https:// www.nhmrc.gov.au/guidelines/publications/e52 (accessed May 2014).

7 Sweet M, Pearson L, Dudgeon P. @IndigenousX: a case study of community-led innovation in digital media. Media International Australia, Incorporating Culture \& Policy [internet] 2013; 149: 104-111.

8 Skehan J, Garvey G, Scott P. Reporting suicide and mental illness for Indigenous Australians. Australian Journalism Review 2005; 27: 25-42. http://www.himh.org.au/_data/assets/pdf_file/0008/4895/Reportingsuicide-and-mental-illness-for-Indigenous-Australians.pdf (accessed May 2014).

9 Stockwell S, Scott P. Fair go for fair reporting. ejournalist [internet] $2001 ; 2$. http://ejournalist.com.au/vln2/stockwell.pdf (accessed May 2014).

10 Plater D. Guidelines to reporting Aboriginal affairs. In: Eggerking K, Plater D, editors. Signposts: a guide to reporting Aboriginal, Torres Strait Islander and ethnic affairs. Sydney: Australian Centre for Independent Journalism, 1992: 28-33.

11 Stoneham MJ, Goodman J, Daube M. The portrayal of Indigenous health in selected Australian media. The International Indigenous Policy Journal [internet] 2014; 5. http://ir.lib.uwo.ca/cgi/viewcontent. cgi?article=1167\&context=iipj (accessed May 2014).

12 NSW Health. Communicating positively. A guide to appropriate Aboriginal terminology. Sydney: NSW Health, 2004. http://www0.health.nsw.gov. au/pubs/2004/pdf/aboriginal_terms.pdf (accessed May 2014).

13 Australian Government Department of Health. National Aboriginal and Torres Strait Islander health plan 2013-2023. http://www.health.gov.au/ natsihp (accessed May 2014).

14 McCallum K, editor. The media and Indigenous policy: how news media reporting and mediatized practice impact on Indigenous policy. A preliminary report. Canberra: University of Canberra, 2012. http://www. canberra.edu.au/media-centre/attachments/pdf_folder/MIP-Report Combined_Final.pdf (accessed May 2014). 